\title{
Concentrações séricas de proteína total, albumina e gamaglobulinas em gatos infectados pelo vírus da imunodeficiência felina
}

\author{
Serum protein, albumin and gamaglobulin concentrations in cats infected with feline \\ immunodeficiency virus
}

\author{
Angela Manetti Armentano Rodrigues ${ }^{\mathrm{I}}$ Marcelo de Souza Zanutto ${ }^{\mathrm{II}}$ \\ Mitika Kuribayashi Hagiwara ${ }^{\text {III }}$
}

RESUMO

A infecção pelo vírus da imunodeficiência dos felinos (VIF) apresenta um curso prolongado, caracterizado por uma fase aguda, em que ocorre a replicação viral no organismo hospedeiro, seguida de um período de menor replicação, no qual o animal é praticamente assintomático. Anos depois, no estádio final da infecção, desenvolve-se a síndrome da imunodeficiência dos felinos. Alguns animais infectados podem desenvolver hipergamaglobulinemia do tipo policlonal, principalmente na fase crônica ou final da infecção. Este fato tem sido atribuído a um distúrbio na produção de citocinas, causado pela infecção viral de linfócitos $T$ CD4+. Não obstante, pouco se sabe a respeito das concentrações de proteínas séricas, especificamente gamaglobulinas, na fase aguda da infecção pelo VIF. Objetivando esclarecer isto, procedeu-se à determinação das proteínas séricas de dez felinos, SRD de ambos os sexos, infectados aos 7 meses de idade com o VIF (clade B), antes da infecção e 4, 8 e 12 meses após. A infecção pelo VIF foi confirmada pela soroconversão, com a presença de anticorpos específicos, pesquisados por meio da técnica de imunoadsorção enzimática (ELISA) e pela demonstração de material genético do vírus (PCR). Outros dez felinos VIF-, da mesma faixa etária foram mantidos como controle. Previamente à infecção experimental, todos os felinos eram negativos ao VIF, fato comprovado pela ausência de anticorpos específicos. A proteína sérica total foi determinada pelo método do buireto e as frações protéicas foram obtidas por eletroforese em tiras de acetato de celulose lidas por densitometria. Verificou-se aumento de gamaglobulinas (2,01 $\left.\pm 0,27 \mathrm{~g} d \mathrm{~L}^{-1}, P<0,0001\right)$ quatro meses após a infecção nos animais infectados. Doze meses após a infecção, não foram observadas diferenças nas concentrações das frações protéicas entre os felinos infectados e os controles.

Palavras-chave: gatos, vírus da imunodeficiência felina, eletroforese, proteínas séricas.

\section{ABSTRACT}

Feline immunodeficiency virus (FIV) infection is known as a lifelong infection of cats. The acute phase corresponds to the period of viral replication in the host organism, followed by a period of lower replication when the animal is asymptomatic. Some years later, at the final stage, an immunodeficiency syndrome subsides. Hypergammaglobulinemia or a polyclonal gammapathy might be seen in some, but not all affected cats, mainly in the chronic phase of infection. This is thought to be due to a disturbance of cytokines production as a result of $T$ CD4 + cells infection. Nonetheless, little is known regarding serum protein, specifically, gammaglobulin concentration in the early phase of FIV infection. Aiming at clarifing this, serum protein concentrations were determined before and 4, 8 and 12 months after FIV infection of ten domestic short-haired, male or female, 7 months old cats (group I). Ten cats of same age were maintained as controls (group II). All cats were FIVnaive cats, as confirmed by ELISA test. After infection, both, ELISA and PCR became positive only for the cats belonging to the group I. Serum protein concentration was measured by biuret method and protein fractions were obtained by electrophoresis on cellulose acetate strips. An increase in the gammaglobulin concentration $(2.01 \pm 0.27 \mathrm{~g} / \mathrm{dL}, P<0.0001)$ could be observed 4 months p.i. in the group I. Twelve months after infection, no differences could be found on protein concentrations between both groups of cats.

Key words: cats, feline immunodeficiency virus; serum protein, electrophoresis.

\section{INTRODUÇÃO}

O vírus da imunodeficiência felina (VIF) é um lentivírus, semelhante ao vírus da imunodeficiência

\footnotetext{
IAutônoma, São Paulo, SP, Brasil.

IDepartamento de Patologia e Clínicas da Escola de Medicina Veterinária da Universidade Federal da Bahia, Salvador, BA, Brasil. IIIDepartamento de Clínica Médica da Faculdade de Medicina Veterinária e Zootecnia (FMVZ), Universidade de São Paulo (USP), Av Prof. Dr. Orlando Marques de Paiva, 87, Cidade Universitária, 05508-900, São Paulo, SP, Brasil. E-mail: mitika.hagiwara@gmail.com.
} 
humana (HIV), porém específico dos felinos. O VIF infecta preferencialmente células mononucleares do sangue periférico e apresenta maior tropismo por linfócitos T CD4+ (PAILLOT, 2005). Gatos infectados pelo VIF desenvolvem anticorpos neutralizantes específicos contra as proteínas p15 e p26 do vírus entre 2 e 4 semanas pi (ENGLISH, 1994), em títulos que se elevam gradualmente em algumas semanas e se mantêm em elevados patamares, como resultado da manutenção da infecção viral (YAMAMOTO, 1988).

No estágio assintomático, que pode durar de meses a anos, apesar da disfunção de células $\mathrm{T}$, a resposta imune, dependente dessas células, permanece aparentemente normal. Muitos pacientes apresentam hipergamaglobulinemia, a qual é considerada uma conseqüência direta da infecção pelo VIF (FLYNN, 1994), embora a disfunção imunológica possa predispor a outras infecções que eventualmente podem contribuir para o aumento das proteínas séricas, especificamente de gamaglobulina (LAPPIN, 1989). Entretanto, gatos livres de outros patógenos e infectados apenas pelo VIF também apresentam aumento progressivo de gamaglobulina (FLYNN, 1994). Cerca de $94 \%$ dos gatos VIF+ apresentam aumento de globulinas e, em 66\% destes animais, esse aumento ocorre em função de uma hipergamaglobulinemia policlonal (SPARKES, 1993).

Além do estímulo antigênico prolongado, que resulta em resposta humoral específica contra o vírus, a infecção de linfócitos T CD4+ pelo VIF induz alteração da produção de citocinas, contribuindo para uma ativação inespecífica de células B, que passam a produzir anticorpos contra antígenos não-virais, incluindo antígenos próprios, já a partir da $6^{\mathrm{a}}$ semana pi, colaborando para a hipergamaglobulinemia policlonal (FLYNN, 1994). Em muitos felinos infectados, principalmente naqueles com infecção crônica, não se observa aumento nas concentrações séricas de gamaglobulinas (HOFMANN-LEHMANN, 1997). Isto pode estar relacionado a um gradual declínio da atividade de linfócitos B, devido à exaustão funcional destas células à medida que a infecção progride, cooperando para uma imunossupressão generalizada, que predispõe a infecções secundárias (FLYNN, 1994).

Embora se saiba que a hipergamaglobulinemia ocorre ao longo da infecção pelo VIF em alguns animais, pouco se conhece a respeito de sua variação na fase inicial da infecção em felinos adultos jovens. $\mathrm{O}$ estímulo antigênico persistente, resultante da replicação viral e da alteração da resposta inata e imune (PETRI, 2002), pode levar ao aumento das proteínas séricas, em especial das gamaglobulinas, como parte da defesa orgânica do hospedeiro, no sentido de limitar a infecção pelo VIF.

\section{MATERIAL E MÉTODOS}

Animais. Foram utilizados vinte gatos, com sete meses de idade, criados no centro de Estudos de Doenças de Cães e Gatos, do Departamento de Clínica Médica da Faculdade de Medicina Veterinária e Zootecnia da Universidade de São Paulo. Os animais foram imunizados contra rinotraqueíte infecciosa, calicivirose, panleucopenia, clamidiose felinas e raiva, com três doses das vacinas Eclipse- $4 \AA$ e Rai-Vac1 ${ }^{\circledR}$ (Fort Dodge Saúde Animal), aos 2, 3 e 4 meses de idade, e receberam tratamento anti-helmíntico (fenbendazole) aos 4, 6, 10 e 14 semanas de idade e, depois, semestralmente. Como preventivo para puliciose, foi utilizado Frontline ${ }^{\circledR}$ (Merial). Todos os animais foram submetidos ao teste ELISA Snap-Combo ${ }^{\circledR}$ FIV-FeLV (IDEXX Laboratories) para a pesquisa de anticorpos anti-VIF e foram considerados não-reagentes a ambos os vírus. Os animais foram divididos aleatoriamente em grupos, I - experimental e II- controle, e alocados em salas separadas. Durante o experimento, os animais foram mantidos em gaiolas individuais, recebiam ração comercial e água ad libitum e tinham acesso ao solário diariamente. Todos os procedimentos adotados foram em consonância com as normas de bem-estar e de bioexperimentação, tendo o projeto recebido o aval da Comissão de Bioética da Unidade.

Infecção experimental com VIF. Os animais do grupo I receberam como inóculo $1 \mathrm{~mL}$ de sangue venoso de um felino portador do vírus da imunodeficiência felina tipo B no estágio terminal da doença. Após a infecção, todos os felinos infectados e os controles foram examinados diariamente quanto às condições físicas. Quatro e oito semanas após a infecção, todos os felinos foram submetidos ao teste ELISA Snap-Combo® FIV-FeLV (IDEXX Laboratories) para a pesquisa de anticorpos anti-VIF. Cinco semanas após a infecção procedeu-se à pesquisa de material genético do vírus por meio da reação em cadeia de polimerase (PCR), realizada no Laboratório do Departamento de Microbiologia e Imunologia do Instituto de Biociências da Universidade Estadual Paulista (UNESP), campus de Botucatu, conforme descrito por HOHDATSU et al. (1998) para a confirmação da infecção nos animais do grupo I. Na reação de PCR, utilizou-se os primers FIV PCR-S2 (5'AAG GAC CTC CAC AGG CTT ATC C -3') e FIV PCRA2 (5'- ACT TCT TGG CAG GCC CTC AG -3'), que amplificam um fragmento de 658 pares de bases (pb). Na reação de nested-PCR utilizou-se os primers FIV NESTED-S (5' - TATTCAAACAGTAAATGG AG -3') e FIV NESTED-A (5' - CTG CTT GTT GTT CTT GAG TT $-3^{\prime}$ ), que amplificam um fragmento de 329pb.

Ciência Rural, v.37, n.1, jan-fev, 2007. 
Coleta de sangue. As amostras para a realização da eletroforese de proteínas séricas foram coletadas previamente à inoculação e 4, 8 e 12 meses pós-inoculação (pi) em tubo Vacutainer, contendo gel para a separação do soro (BD Vacutainer ${ }^{\circledR}$ Blood Collection Tubes). O soro obtido foi mantido em tubos tipo Eppendorf a $-20^{\circ} \mathrm{C}$ até o momento da realização das análises.

Determinação da proteína sérica total. A proteína sérica total foi dosada pelo método do biureto, em equipamento automatizado Liasys ${ }^{\circledR}$.

Fracionamento de proteínas séricas por eletroforese em gel de acetato de celulose. Utilizou-se equipamentos BioSystem ${ }^{\circledR}$ (cubeta e chamber modelo 280, kit de aplicadores micro 8 e fitas de acetato de celulose para eletroforese tamanho 5,7cm x $14 \mathrm{~cm}$ ). As amostras de soro aplicadas às tiras de eletroforese foram submetidas a uma corrente elétrica de $220 \mathrm{~V}$ por 35 minutos em tampão Tris-Veronal de pH 8,8, coradas com o corante de Ponceau S, desidratadas em metanol absoluto por dois minutos, transparentizadas por três minutos em solução transparentizadora (ácido acético$8 \mathrm{~mL}$ e metanol-42mL) e secadas em estufa pré-aquecida a $65^{\circ} \mathrm{C}$ por sete minutos. As tiras foram lidas pelo método de densitometria em aparelho Imaging Densitometer, modelo GS-700 BIO RAD ${ }^{\circledR}$, para se obter os valores relativos de cada fração.

Análise estatística. As concentrações séricas de cada uma das frações foram obtidas relacionando-se os valores percentuais com a concentração sérica de proteína total. Os resultados foram expressos em $\mathrm{g} \mathrm{dL}^{-1} \mathrm{e}$ então submetidos à análise estatística, inicialmente para a verificação de normalidade da distribuição, utilizando-se programa estatístico $\mathrm{SAS}^{\circledR}$, e posteriormente submetidos ao teste ANOVA, para comparação das médias entre os momentos e entre os grupos.

\section{RESULTADOS}

Sinais clínicos, soroconversão e confirmação da infecção. Todos os felinos infectados apresentaram picos febris, aumento de linfonodos periféricos e dos linfonodos abdominais respectivamente a partir das $3^{\mathrm{a}}, 6^{\mathrm{a}}$ e $12^{\mathrm{a}} \stackrel{\mathrm{a}}{\text { semanas }}$ pi. A partir da quarta semana, observou-se esplenomegalia em oito e hepatomegalia em cinco dos gatos infectados. A infecção pelo VIF foi comprovada pela soroconversão de todos os gatos inoculados, 4 e 8 semanas pi, por meio de ELISA, e confirmada aos 5 meses pi pela amplificação do material genético do vírus por meio de PCR (Figura 1). Os felinos do grupo II permaneceram saudáveis, não reagentes ao teste ELISA e negativos à amplificação de material genético viral a partir do sangue periférico desses animais.

Proteína sérica total e fracionamento de proteínas séricas por eletroforese em gel de acetato de celulose. A proteína total, em ambos os grupos, apresentou um aumento gradativo no decorrer do estudo. Nos animais do grupo I, verifica-se aumento significativo da proteína total já aos 4 meses pi, comparado ao momento zero $(\mathrm{P}<0,0001)$. Aos 8 e 12 meses pi, não houve diferença estatística em relação aos 4 meses pi. No grupo II, esse aumento é mais lento, só havendo diferença significativa na concentração sérica média de proteína total aos 12 meses pi, em relação aos momentos zero e $1(\mathrm{P}=0,0043)$. Aos 12 meses pi, em ambos os grupos, observa-se uma discreta hiperproteinemia. (Tabela 1; Figura 2, A).

As concentrações séricas médias de albumina permaneceram sem alteração entre os momentos analisados em ambos os grupos. Entretanto, aos 4, 8 e 12 meses pi, o grupo I apresentou valores estatisticamente menores em relação ao grupo II (respectivamente $\mathrm{P}=0,0389 ; \mathrm{P}=0,0026 ; \mathrm{P}<0,0001$ ) (Figura 2, B), o qual apresentou, aos 12 meses pi, valor médio de albumina acima do limite superior da faixa de referência (Tabela 2).

O grupo I apresentou aumento significativo da concentração sérica de gamaglobulina já no $4^{\circ}$ mês pi $(\mathrm{P}<0,0001)$, quando comparado ao momento anterior,

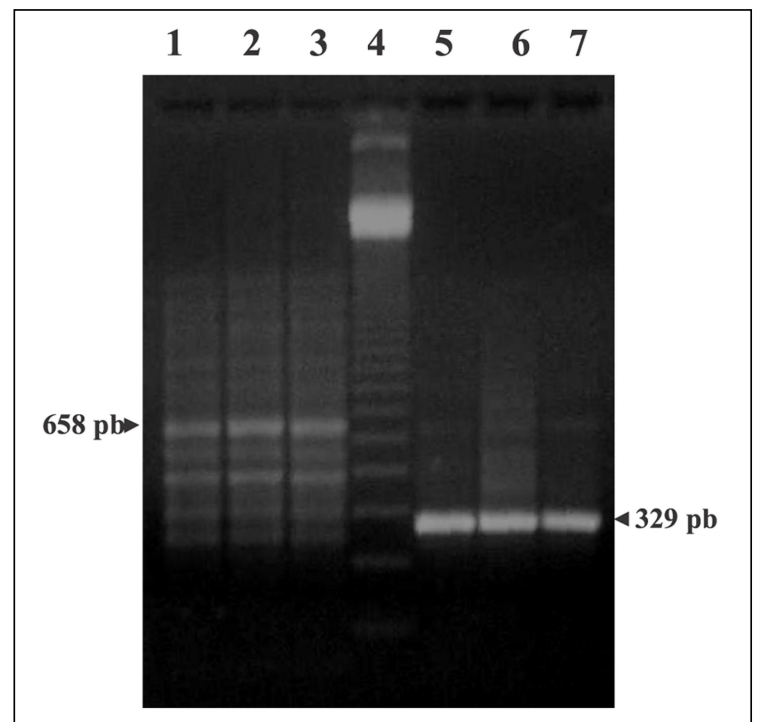

Figura 1 - Visualização de material genético amplificado, específico de VIF, da reação de PCR e PCR-Nested. Nas colunas 1, 2 e 3, são observadas bandas de 658 pares de base (pb) com material genético amplificado da reação de PCR; na coluna 4, o marcador de 123 pb; e nas colunas 5, 6 e 7, bandas com material genético de 329 pb amplificado da reação de PCRNested. 
Tabela 1 - Valores médios e desvio padrão de proteína total dos grupos I ${ }^{1}$ e II $^{2}$ pré-inoculação e aos 4 , 8 e 12 meses p.i.

\begin{tabular}{lcc}
\hline Proteína total & Grupo I & Grupo II \\
\hline Pré-inoculação & $6,21 \pm 0,67 \mathrm{~g} / \mathrm{dl}_{\mathrm{Bb}}$ & $7,24 \pm 1,03 \mathrm{~g} / \mathrm{dl}_{\mathrm{Ba}}$ \\
4 meses pi & $7,39 \pm 0,59 \mathrm{~g} / \mathrm{dl}_{\mathrm{Aa}}$ & $7,19 \pm 0,99 \mathrm{~g} / \mathrm{dl}_{\mathrm{Ba}}$ \\
8 meses pi & $7,63 \pm 0,62 \mathrm{~g} / \mathrm{dl}_{\mathrm{Aa}}$ & $7,88 \pm 0,61 \mathrm{~g} / \mathrm{dl}_{\mathrm{BAa}}$ \\
12 meses pi & $7,93 \pm 0,65 \mathrm{~g} / \mathrm{dl}_{\mathrm{Aa}}$ & $8,42 \pm 0,42 \mathrm{~g} / \mathrm{dl}_{\mathrm{Aa}}$ \\
\hline
\end{tabular}

${ }^{1}$ grupo experimental; ${ }^{2}$ grupo controle; A e B = diferença estatística entre os momentos de cada grupo; a e b = diferença estatística entre os grupos em cada momento; pi = pós-inoculação. Valor de referência: 5,4-7,8 g/dl (KANEKO, 1997).

mantendo-se constante nos momentos seguintes (Tabela 3). O grupo II apresentou aumento significativo desta fração apenas a partir do $8^{\circ}$ mês p.i. $(\mathrm{P}<0,0001)$, mantendo-se no momento 3 . Aos 4 meses pi, o valor de gamaglobulina foi significativamente maior no grupo I $(2,01 \pm 0,27, \mathrm{P}<0,0001)$ do que no grupo II. Nos momentos seguintes, não houve diferença estatística entre os dois grupos, apesar de o grupo I apresentar valores médios de gamaglobulinas no limite superior da faixa de referência (Tabela 3; Figura 2, C). O perfil eletroforético de um dos felinos infectados está apresentado na figura 3. Nos demais momentos de ambos os grupos, apesar das variações, os valores médios de proteína total, albumina e gamaglobulinas permaneceram dentro da faixa de referência.

\section{DISCUSSÃO}

As manifestações clínicas apresentadas pelos felinos infectados (febre, aumento dos linfonodos periféricos e, principalmente, dos abdominais, esplenomegalia e hepatomegalia) são citadas por YAMAMOTO et al. (1988) e ENGLISH et al. (1994) em felinos infectados pelo VIF, principalmente na fase aguda da infecção. Depressão ou alterações comportamentais, indicativas de comprometimento do sistema nervoso central, não foram observadas, refletindo provavelmente a menor patogenicidade e virulência da cepa viral envolvida. A confirmação da infecção foi demonstrada por meio da soroconversão e da reação positiva para a PCR específica.

Em geral, a fase aguda da infecção se inicia por volta de 4 semanas p.i, tendo duração média de 4 meses. Após esse período, a replicação viral ocorre mais lentamente, porém há a persistência do VIF no organismo hospedeiro (ETTINGER \& FELDMAN, 2000). A linfoadenomegalia persistente observada em todos os felinos infectados é consistente com a hiperplasia linfóide associada à presença do vírus, conforme é citado por YAMAMOTO et al. (1988). Como

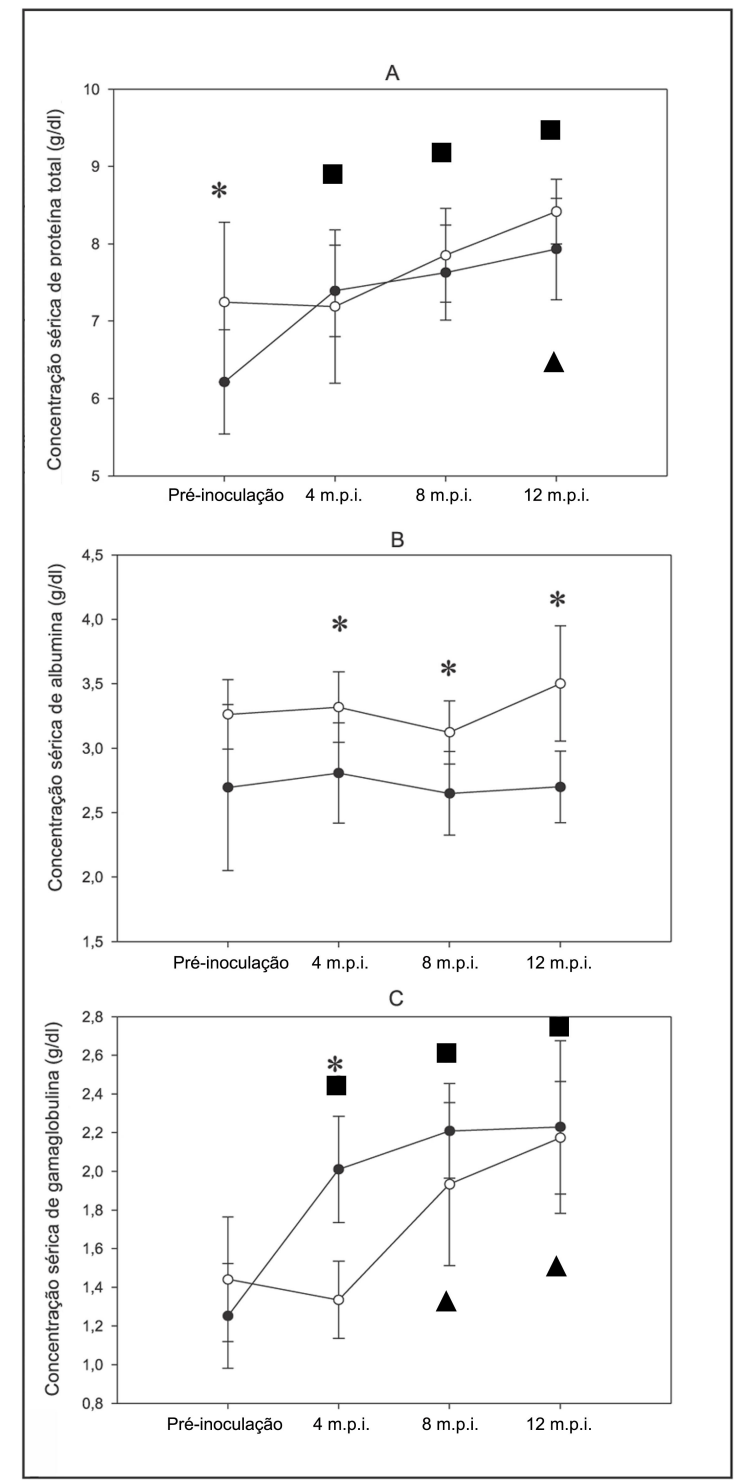

Figura 2 - Valores médios e desvio padrão das concentrações séricas das frações protéicas de (A) proteína total, (B) albumina e (C) gamaglobulina, nos diferentes momentos. • = Grupo I; o = Grupo II; m.p.i. = meses pós-infecção; diferença estatística entre os grupos $(*)$, entre momentos do grupo I ( $)$ e entre os momentos do grupo II $(\boldsymbol{\Delta})$.

conseqüência, o estímulo antigênico representado pelo VIF resulta na produção de anticorpos (OBERT \& HOOVER, 2002), refletindo no aumento da fração gamaglobulínica observada nos felinos infectados ao quarto mês pós-infecção.

O aumento de gamaglobulina pode também estar relacionado à ativação policlonal inespecífica das células B. O VIF tem maior tropismo por células T CD4+ (ENGLISH, 1994), o que resulta no aumento da produção de IL-6, entre outras interleucinas

Ciência Rural, v.37, n.1, jan-fev, 2007. 
Tabela 2 - Valores médios e desvio padrão de albumina dos grupos $\mathrm{I}^{1}$ e $\mathrm{II}^{2}$ pré-inoculação e aos 4,8 e 12 meses pi.

\begin{tabular}{lcc}
\hline Albumina & Grupo I & Grupo II \\
\hline Pré-inoculação & $2,69 \pm 0,64 \mathrm{~g} / \mathrm{dl}_{\mathrm{Aa}}$ & $3,26 \pm 0,59 \mathrm{~g} / \mathrm{dl}_{\mathrm{Aa}}$ \\
4 meses pi & $2,81 \pm 0,39 \mathrm{~g} / \mathrm{dl}_{\mathrm{Ab}}$ & $3,32 \pm 0,61 \mathrm{~g} / \mathrm{dl}_{\mathrm{Aa}}$ \\
8 meses pi & $2,65 \pm 0,32 \mathrm{~g} / \mathrm{dl}_{\mathrm{Ab}}$ & $3,12 \pm 0,28 \mathrm{~g} / \mathrm{dl}_{\mathrm{Aa}}$ \\
12 meses pi & $2,70 \pm 0,28 \mathrm{~g} / \mathrm{dl}_{\mathrm{Ab}}$ & $3,50 \pm 0,33 \mathrm{~g} / \mathrm{dl}{ }_{\mathrm{Aa}}$ \\
\hline
\end{tabular}

${ }^{1}$ grupo experimental; ${ }^{2}$ grupo controle; A e B = diferença estatística entre os momentos de cada grupo; a e b = diferença estatística entre os grupos em cada momento; pi = pós-inoculação. Valor de referência: 2,1-3,3g/dl (KANEKO, 1997).

(LAWRENCE, 1995). A IL-6 pode causar uma ativação policlonal inespecífica das células B (FLYNN, 1994), resultando na produção de anticorpos contra os imunógenos contidos nos bancos de memória individuais (GRANT, 1995). A ativação inespecífica de células B pode estar relacionada à presença de linfomas em gatos VIF positivos, nos quais as neoplasias linfóides que se desenvolvem são, em geral, originárias de células B (ENGLISH, 1994).

O aumento da concentração sérica de gamaglobulina ocorreu de forma mais gradual a partir do quarto mês, refletindo provavelmente menor estímulo antigênico, coincidindo com o período de menor agressão viral ao organismo hospedeiro (ETTINGER \& FELDMAN, 2000). Ultrapassada a fase aguda, ocorre uma estabilização dos títulos de anticorpos devido à diminuição da carga viral, em virtude da resposta imune do hospedeiro (YAMAMOTO, 1988). Entretanto, o vírus permanece no hospedeiro e a infecção viral é sustentada, embora em níveis mais baixos, assim como a produção de anticorpos contra componentes protéicos do vírus (HARTAMANN, 1998). Os anticorpos permanecem em
Tabela 3 - Valores médios e desvio padrão de gamaglobulina dos grupos I $^{1}$ e II $^{2}$ pré-inoculação e aos 4, 8 e 12 meses pi

\begin{tabular}{lcc}
\hline Gama-globulina & Grupo I & Grupo II \\
\hline Pré-inoculação & $1,25 \pm 0,27 \mathrm{~g} / \mathrm{dl}$ Ba & $1,44 \pm 0,32 \mathrm{~g} / \mathrm{dl}_{\mathrm{Ba}}$ \\
4 meses pi & $2,01 \pm 0,27 \mathrm{~g} / \mathrm{dl}_{\mathrm{Aa}}$ & $1,33 \pm 0,20 \mathrm{~g} / \mathrm{dl}_{\mathrm{Bb}}$ \\
$\mathbf{8}$ meses pi & $2,21 \pm 0,24 \mathrm{~g} / \mathrm{dl}_{\mathrm{Aa}}$ & $1,93 \pm 0,42 \mathrm{~g} / \mathrm{dl}_{\mathrm{Aa}}$ \\
12 meses pi & $2,23 \pm 0,45 \mathrm{~g} / \mathrm{dl}_{\mathrm{Aa}}$ & $2,17 \pm 0,29 \mathrm{~g} / \mathrm{dl}{ }_{\mathrm{Aa}}$ \\
\hline
\end{tabular}

${ }^{1}$ grupo experimental; ${ }^{2}$ grupo controle; A e B = diferença estatística entre os momentos de cada grupo; a e b = diferença estatística entre os grupos em cada momento; pi = pós-inoculação. Valor de referência: 0,9 - 2,2g/dl (KANEKO, 1997).

níveis detectáveis quase até o final da vida do animal (HOFMANN-LEHMANN, 1997). Aumento gradual na concentração sérica de gamaglobulinas também ocorreu nos felinos do grupo controle, a partir dos 8 meses pi, estabilizando-se aos 12 meses pi. Isso se deve provavelmente ao desenvolvimento da imunidade humoral. Segundo PASTORET et al. (1998), os filhotes passam a produzir anticorpos ativamente a partir da quarta até a quinta semana de idade, ocorrendo seu aumento gradual à medida que se desenvolve a imunidade humoral, até atingir os níveis de adultos, o que ocorre ao redor de 1 ano e meio de idade.

Também se observou aumento nas concentrações séricas de proteína total, o que pode ser creditado ao aumento de gamaglobulina, já que, no grupo I, a concentração sérica de albumina permaneceu praticamente inalterada nos diferentes momentos estudados. O mesmo ocorreu com os felinos não infectados que, no entanto, apresentaram valores de albumina sérica discretamente superiores desde o momento inicial.

Conclui-se, portanto, que, nos animais infectados pelo VIF, houve aumento significativo de

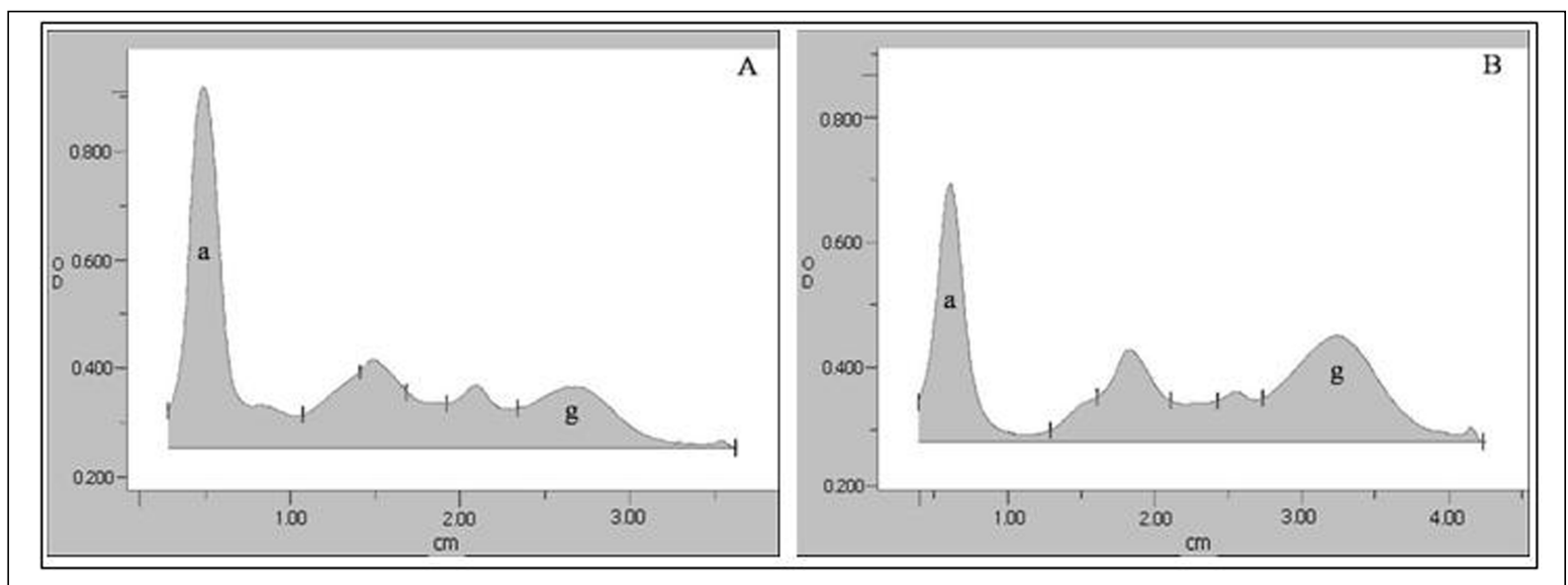

Figura 3 - A: perfil eletroforético de proteínas séricas do animal nº 9 do grupo 1, pré-inoculação. B: perfil eletroforético de proteínas séricas do mesmo animal de A, oito meses após a inoculação com VIF. a = fração de albumina; $\mathrm{g}=$ fração de gamaglobulina.

Ciência Rural, v.37, n.1, jan-fev, 2007. 
gamaglobulinas aos 4 meses pi, refletindo a resposta imune humoral nos primeiros meses que se seguiram à infecção, e que a concentração sérica de albumina manteve-se significativamente menor em relação aos felinos não-infectados, provavelmente devido à diminuição da síntese de albumina nos processos inflamatórios em geral (KANEKO, 1997) e, neste caso em particular, devido à persistência da infecção pelo VIF.

\section{REFERÊNCIAS}

ENGLISH, R.V. et al. Development of clinical disease in cats experimentally infected with feline immunodeficiency virus. Journal of Infectious Disease, v.170, p.543-552, 1994.

ETTINGER, S.J.; FELDMAN, E.C. Textbook of veterinary internal medicine. 5.ed. Philadelphia: Saunders, 2000. V.1

FLYNN, J.N. et al. Polyclonal B-cell activation in cats infected with feline immunodeficiency virus. Immunology, v.81, p.626630, 1994.

GRANT, C.K. Immunoglobulin changes associated with feline immunodeficiency virus infection. In: WILLETT, B.J.; JARRET, O. Feline immunology and immunodeficiency. New York: Oxford University, 1995. Cap.11, p.170-189.

HARTMANN, K. Feline immunodeficiency virus infection: an overview. Veterinary Journal, v.155, n.2, p.123-137, 1998.

HOFMAN-LEHMANN, R. et al. Parameters of disease progression in long-term experimental feline retrovirus (feline immunodeficiency virus and feline leukemia virus) infection: hematology, clinical chemistry and lymphocyte subsets, Clinical and Diagnostic Laboratorial immunology, v.4, n.1, p.33-42, 1997.
HOHDATSU, T. et al. Genetic subtyping and epidemiological study of feline immunodeficiency virus by nested polymerase chain reaction-restriction fragment length polymorphism analysis of the gag gene. Journal of Virological Methods, v.70, p.107-111, 1998.

KANEKO, J.J. et al. Clinical biochemistry of domestic animals. 5.ed. San Diego: Academic, 1997. 932p.

LAPPIN, R.M. et al. Clinical feline toxoplasmosis: Serologic diagnosis and therapeutic management of 15 cases. Journal of Veterinary Internal Medicine, v.3, n.3, p.139-143, 1989.

LAWRENCE, C.E. et al. Cytokine production by cats infected with feline immunodeficiency virus - a longitudinal-study, Immunology, v.85, n.4, p.568-574, 1995.

OBERT, L.A.; HOOVER, E.A. Early pathogenesis of transmucosal feline immunodeficiency virus infection. Journal of Virology, v.76, n.12, p.6311-6322, 2002.

PAILLOT, R. et al. Toward a detailed characterization of feline immunodeficiency virus-specific $\mathrm{T}$ cell immune responses and mediated immune disorders. Veterinary Immunology and Immunopathology, v.106, n.1-2, p.1-14, 2005.

PASTORET, P-P. et al. Handbook of vertebrate immunology. San Diego: Academic, 1998. 673p.

PETRI, G. Atividade oxidativa dos neutrófilos em gatos infectados pelo vírus da imunodeficiência felina (FIV). 2002. 55f. Tese (Doutorado em Clínica Veterinária) Universidade de São Paulo.

SPARKES, A.H. et al. Feline immunodeficiency virus infection: Clinicopathological findings in 90 naturally occurrin cases, Journal of Veterinary Internal Medicine, v.7, p.85-90, 1993.

YAMAMOTO, J.K. et al. Pathogenesis of experimentally induced feline immunodeficiency virus infection in cats. American Journal of Veterinary Research, v.49, p.12461258, 1988. 